Article

\title{
Investigation into Micro-Hardness and Wear Resistance of 316L/SiC Composite Coating in Laser Cladding
}

\author{
Guofu Lian ${ }^{1}$, Chenmin Zhao ${ }^{1}$, Yang Zhang ${ }^{2, *}$, Meiyan Feng ${ }^{1}$ and Jibin Jiang ${ }^{1}$ \\ 1 School of Mechanical and Automotive Engineering, Fujian University of Technology, Fuzhou 350118, China; \\ gflian@mail.ustc.edu.cn (G.L.); chenminzhao@smail.fjut.edu.cn (C.Z.); myfeng@ipe.ac.cn (M.F.); \\ jibinj@fjut.edu.cn (J.J.) \\ 2 School of Engineering + Technology, Western Carolina University, Cullowhee, NC 28723, USA \\ * Correspondence: yzhang@wcu.edu; Tel.: +1-(828)-227-2564
}

Received: 22 March 2020; Accepted: 28 April 2020; Published: 1 May 2020

check for updates

\begin{abstract}
In order to improve the performance of the cladding layer, this study used the Taguchi orthogonal design to investigate the influence of laser power, scanning speed, gas flow, and SiC powder ratio on the micro-hardness and wear volume of the cladding layer. The results indicate that the $\mathrm{SiC}$ powder ratio was the major factor that had the main impact on the micro-hardness and wear volume of the cladding layer. The contribution of $\mathrm{SiC}$ powder ratio on the micro-hardness and wear volume are $92.08 \%$ and $79.39 \%$, respectively. Through signal to noise ratio conversion and combining grey relational analysis, the multiple objectives optimization was attained. With the target of maximizing the micro-hardness and minimizing the wear volume simultaneously, grey relational analysis was applied to obtain the optimal processing parameters set and predict the corresponding grey relational grade. The error rate was $5.3 \%$ between the prediction and experimental validation. This study provides the guidance for optimizing multiple goals at the same time using grey relational analysis about the coating properties deposited by laser cladding in actual industrial applications. It provided theoretical basis for the processing parameters optimization with targeting the micro-hardness and wear resistance.
\end{abstract}

Keywords: laser cladding; composite; micro-hardness; wear volume; grey relational analysis

\section{Introduction}

Laser cladding is a coating technology, which use the high-energy laser beam irradiating on the substrate surface and powder, causing the powder rapid melting and cooling to form the desired metallic bond coating with the substrate [1-3]. Due to the high energy density, high efficiency, outstanding mechanical and physical properties, laser cladding has been widely used on surface restoration to form low dilution rate condensed coating for multiple purposes [4,5]. Composite material coating restoration has been rapidly developed in the recent years [6,7]. The 316L stainless steel powder is widely used in industry because of its low cost, corrosion resistance, and self-fluxing [8]. However, the limitation of 316L also exists due to its low hardness and inadequate wear resistance [9]. With the development of composite material, these limitations could be improved by adding reinforcement particles [10]. SiC particle possesses the advantage of high micro-hardness and wear resistance. Thus, $\mathrm{SiC}$ is a favorable reinforcement material used in composite materials [11]. This study focuses on investigating the micro-hardness and wear resistance of the cladding layer manufactured by $\mathrm{SiC}$ reinforced 316L stainless steel powder in laser cladding.

Wen et al. found the micro-hardness and corrosion resistance of 316L were effectively improved by conducting the laser cladding in the solution with $3.5 \mathrm{wt} \% \mathrm{NaCl}$ [12]. Mei et al. studied the selective laser cladding with 316L and Inconel 718. They found the contacting zone between these two 
materials had different micro-hardness and micro-structure, with pores and cracks [13]. Murkute et al. investigated 316L coating on the AISI 1018 steel substrate, and found the nano-indentation hardness was reduced with the increasing scanning speed [14]. Riquelme et al. deposited $\mathrm{Al}, \mathrm{Si}$, $\mathrm{Ti}$ and $\mathrm{SiC}$ composite coating on ZE41 magnesium alloy. They discovered that the micro-hardness and mechanical property was improved with ratio of alloying elements [15]. Ramakrishnan et al. manufactured SiC reinforced Haynes 282 (HY282) functional gradient super alloy with different $\mathrm{SiC}$ composition, structure and property. They found the micro-hardness and wear resistance of the super alloy were significant improved with the increased $\mathrm{SiC}$ particles composition [16]. Zhao et al. produced $8.5 \mathrm{vol} \% \mathrm{SiC} / \mathrm{AlSi} 10$ $\mathrm{Mg} \mathrm{SiC}$ ceramic reinforced Al-based composites by selective laser melting. They addressed that the nano-hardness and elastic modulus in the center and boundary were better than the conventional materials [17].

Regarding multiple objectives optimization, Ma et al. designed a polynomial model of dilution rate and residual stress through response surface methodology. The minimal dilution rate and residual stress was obtained by using the quadratic models as the constraint functions and multi-objective quantum-behaved particle swarm optimization. In the end, the optimal processing parameters were achieved and high entropy alloy coating was produced [18]. Sohrabpoor developed an adaptive neuro-fuzzy inference system (ANFIS), which is capable to model the response based on the processing parameters in the laser powder deposition process. The prediction accuracy was improved by associating the ANFIS with imperialist competitive algorithm [19]. Shi et al. utilized Taguchi orthogonal array (OA) to reduce number of experiments and Technique for Order Preference by Similarity to an Ideal Solution (TOPSIS) to complete multiple objectives optimization in the laser cladding. The improved micro-hardness and wear resistance of the gradient composite coating were predicted and verified by ANOVA method [20].

The current research focus on 316L stainless steel powder laser cladding are primarily concentrated on improving the micro-hardness and wear resistance by adding reinforcement material [21-23]. The influence of laser cladding processing parameters and reinforcement composite composition on the micro-hardness and wear volume in the cladding layer was rarely discovered. The performance of the cladding layer determines the successful of restoration. The micro-hardness and wear resistance are important indicators for the performance of cladding layer. This study was carried out with Taguchi orthogonal design for initial experimental runs. After analysis on the processing parameters, optimization and prediction were conducted with grey relational analysis to obtain the maximal micro-hardness and minimal wear volume simultaneously in cladding layer deposited by 316L stainless steel and SiC composite.

\section{Materials and Methods}

The ASTM-5140 steel was selected as the substrate in this study with the size of $40 \mathrm{~mm} \times$ $20 \mathrm{~mm} \times 10 \mathrm{~mm}$, in the background of crankshaft restoration in industrial application; its elemental composition was shown in Table 1 . The powder used in laser cladding process was the mixture of 316L stainless steel powder and $\mathrm{SiC}$ powder produced by Xiangcheng Yuteng Ceramic Product CO., LTD (Zhangzhou, China) with both particle sizes ranging from 48 to $106 \mu \mathrm{m}$, which met the requirement for the equipment specifications. Table 1 also shows the elemental composition of the aforementioned two type of cladding powders.

Table 1. Elemental composition (wt. \%) of W6Mo5Cr4V2 high-speed steel powder.

\begin{tabular}{cccccccccc}
\hline \multirow{2}{*}{ Material } & \multicolumn{8}{c}{ Element (wt. \%) } \\
\cline { 2 - 10 } & $\mathbf{C}$ & $\mathbf{S i}$ & $\mathbf{O}$ & $\mathbf{N i}$ & $\mathbf{C r}$ & $\mathbf{N b}$ & $\mathbf{S i C}$ & $\mathbf{N}$ & $\mathbf{F e}$ \\
\hline ASTM-5140 & $0.37-0.44$ & $0.17-0.37$ & - & $\leq 0.30$ & $0.80-1.10$ & - & - & - & Rest \\
316L & 0.03 & 1 & 0.1 & $10-14$ & $16-18$ & - & - & 0.1 & Rest \\
SiC & - & - & - & - & - & 0.05 & Rest & - & 0.02 \\
\hline
\end{tabular}


The laser cladding system used in this study was schematically illustrated in Figure 1. Four sub-systems build up the whole system, consisting control system, laser system, chamber system, powder and gas delivery system. The whole system was operated under the PLC control system made by Mitsubishi, Japan. The laser system included YLS-3000 laser generator and SX14-012PULSE laser pulse control produced by IPG Photonics (Burbach, Germany). The generated laser energy was transmitted into the FDH0273 laser cladding nozzle with $300 \mathrm{~mm}$ focal length (Lasermech, Novi, MI, USA) to complete the laser cladding process in the chamber system, where the M-710iC/50 industrial robot (FANUC, Yamanashi, Japan) and the TFLW-4000WDR-01-3385 water cooling system (Sanhe Tongfei, Sanhe, China) were equipped. Argon gas was utilized as the carrier and protective gas by the CR-PGF-D-2 powder and gas delivery system (Songxing, Fuzhou, China) during the cladding process.

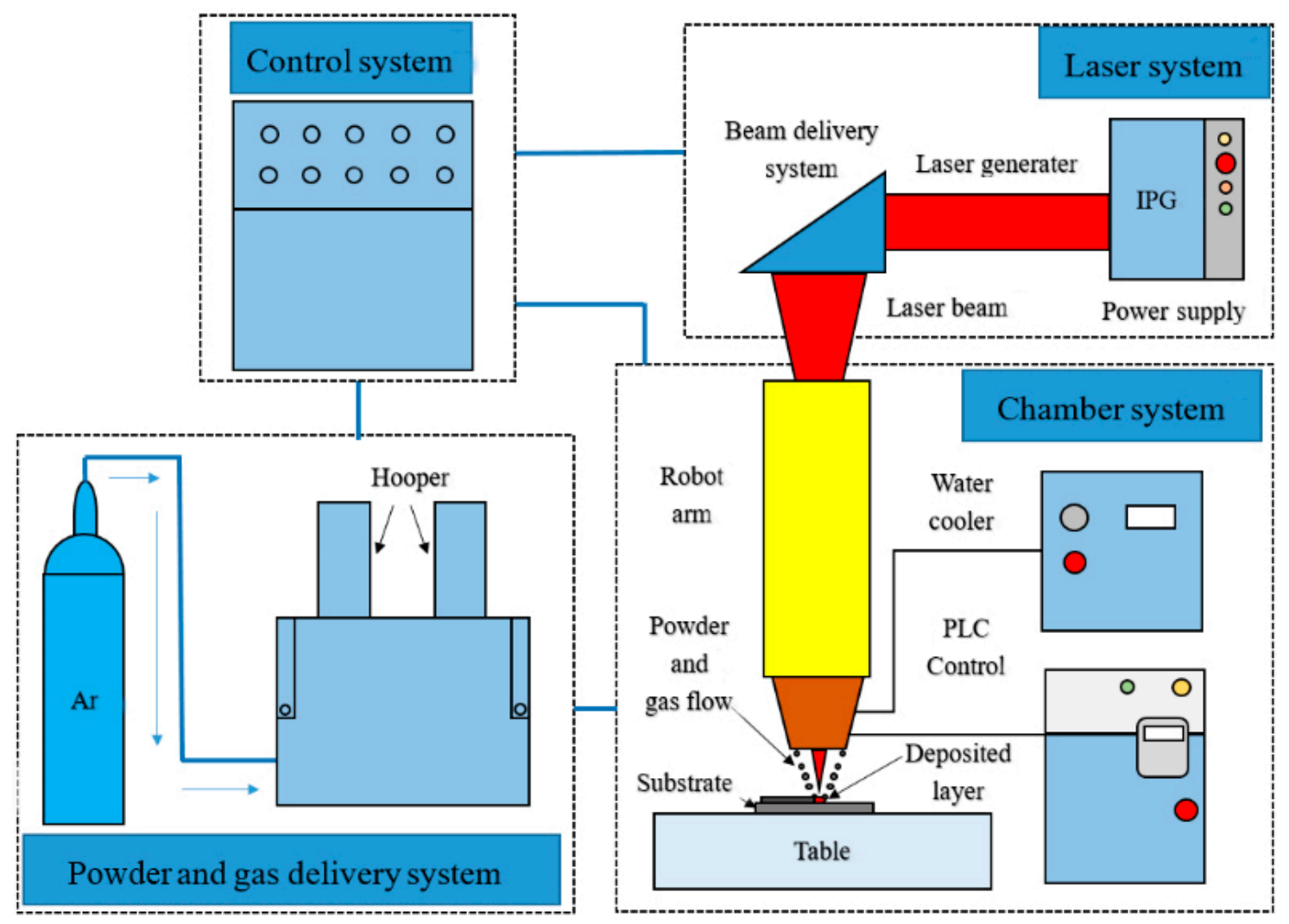

Figure 1. Laser cladding system schematic illustration.

Before the laser cladding process, the surface of ASTM-5140 steel substrate was cleaned with acetone. In the preparation of the laser cladding powder mixture, the $316 \mathrm{~L}$ stainless steel powder and $\mathrm{SiC}$ powder were mixed in a MITR-YXQM-2L ball mill at a $400 \mathrm{rpm}$ speed for $30 \mathrm{~min}$, and then dried in a vacuum dryer at $80^{\circ} \mathrm{C}$ for another $30 \mathrm{~min}$ afterwards [24,25]. This study utilized an orthogonal array with five factors and four levels, with one factor as blank. The other four factors were the four processing parameters to be investigated in this study, as shown in Table 2. A full factorial experimental design would require $4^{4}=256$ runs to include all the combinations in the four factors and four levels design. The Taguchi orthogonal design is a method of designing the experiment, which reduces the number of runs versus the full factorial design and obtains the optimal combination through orthogonal matrix [26,27]. Thus, a $\mathrm{L}_{16}\left(4^{4}\right)$ Taguchi orthogonal design was developed with 16 runs, as shown in Table 3. 
Table 2. Orthogonal experimental design for four factors and four levels.

\begin{tabular}{ccccccc}
\hline Processing & Notation & Unit & \multicolumn{5}{c}{ Levels } \\
\cline { 4 - 7 } Parameter & & & $\mathbf{1}$ & $\mathbf{2}$ & $\mathbf{3}$ & $\mathbf{4}$ \\
\hline Laser Power & $\mathrm{LP}$ & $\mathrm{W}$ & 1200 & 1400 & 1600 & 1800 \\
Scanning Speed & $\mathrm{SS}$ & $\mathrm{mm} / \mathrm{s}$ & 6 & 7 & 8 & 9 \\
Gas Flow & $\mathrm{GF}$ & $\mathrm{L} / \mathrm{h}$ & 900 & 1100 & 1300 & 1500 \\
$\mathrm{SiC}$ Powder Ratio & $\mathrm{PR}$ & $\%$ & 0 & 10 & 20 & 30 \\
\hline
\end{tabular}

Table 3. $\mathrm{L}_{16}\left(4^{4}\right)$ Taguchi orthogonal experimental design and results.

\begin{tabular}{|c|c|c|c|c|c|c|}
\hline Run & Lase Power (W) & $\begin{array}{c}\text { Scanning } \\
\text { Speed }(\mathrm{mm} / \mathrm{s})\end{array}$ & $\begin{array}{l}\text { Gas Flow } \\
\text { (L/h) }\end{array}$ & $\begin{array}{c}\text { Powder } \\
\text { Ratio (\%) }\end{array}$ & $\begin{array}{l}\text { Micro-Hardness } \\
\text { (HRC) }\end{array}$ & $\begin{array}{l}\text { Wear Volume } \\
\quad\left(\mathrm{mm}^{3}\right)\end{array}$ \\
\hline 1 & 1400 & 9 & 1100 & 0 & 19.0 & 0.0042296 \\
\hline 2 & 1400 & 8 & 900 & 10 & 24.9 & 0.0034816 \\
\hline 3 & 1200 & 8 & 1300 & 20 & 39.1 & 0.0020500 \\
\hline 4 & 1400 & 7 & 1500 & 20 & 50.6 & 0.0016755 \\
\hline 5 & 1600 & 9 & 900 & 20 & 40.0 & 0.0009220 \\
\hline 6 & 1400 & 6 & 1300 & 30 & 66.3 & 0.0003904 \\
\hline 7 & 1600 & 6 & 1500 & 10 & 37.1 & 0.0020868 \\
\hline 8 & 1800 & 6 & 1100 & 20 & 47.4 & 0.0003091 \\
\hline 9 & 1600 & 7 & 1300 & 0 & 18.0 & 0.0032789 \\
\hline 10 & 1200 & 9 & 1500 & 30 & 45.7 & 0.0008109 \\
\hline 11 & 1200 & 7 & 1100 & 10 & 25.6 & 0.0028956 \\
\hline 12 & 1800 & 8 & 1500 & 0 & 17.4 & 0.0032958 \\
\hline 13 & 1800 & 7 & 900 & 30 & 47.8 & 0.0003133 \\
\hline 14 & 1200 & 6 & 900 & 0 & 18.2 & 0.0054664 \\
\hline 15 & 1600 & 8 & 1100 & 30 & 57.9 & 0.0004863 \\
\hline 16 & 1800 & 9 & 1300 & 10 & 28.0 & 0.0039519 \\
\hline
\end{tabular}

The laser cladding process was conducted following the setup in Table 3, one sample was obtained for each run. After the completion, the 16 samples were prepared by linear cutting, grinding, and aqua regia immersing for measurement and testing in latter steps. After the sample preparation, the micro-hardness was tested by a 402TS micro-hardness tester (HDNS, Shanghai, China) with applying $500 \mathrm{~g}$ force for 30-s duration. The measurement location was at the subsurface of the clad to guarantee the accuracy, since the incomplete melted material on top surface of the clad, while the bottom layer of the clad was diffused by the $\mathrm{Cr}$ and $\mathrm{C}$ element from the substrate. The wear resistance was interpreted by the indicator of wear volume. The wear volume was tested by a UMT-2 high load scratch tester (Bruker, Billerica, MA, USA) applying constant reciprocating scratch for $30 \mathrm{~min}$. Then the 3D morphology was obtained for the scratch surface on each sample by white light interferometry. Afterwards, the wear volume was acquired for each sample [24,25]. Table 3 shows the micro-hardness and wear volume for each sample clad manufactured under different processing parameters. For instance, it can be found that the micro-hardness of pure 316L stainless steel coating was in a range of $17.4 \mathrm{HRC}$ to $19.0 \mathrm{HRC}$, which can be derived from run \#1, \#9, \#12, and \#14 (0\% SiC powder ratio).

Signal to noise ratio $(\mathrm{S} / \mathrm{N})$ is the indicator of the stability in experiments. The conversion from the raw data to $\mathrm{S} / \mathrm{N}$ reduces the variability in the raw data resulted from the uncontrollable noise factor, where the noise factor lead to unpredictable error on the result. $\mathrm{S} / \mathrm{N}$ indicates the influence of error on the result by measuring the difference between the expected result value and actual result value [27-29]. Therefore, $\mathrm{S} / \mathrm{N}$ conversion is an applicable tool used for optimization in data analysis [30,31]. According to the purpose of this study: the micro-hardness is expected to be the larger the better, while the wear volume is expected to be the smaller the better, Equation (1) and (2) were used to covert the actual 
values shown in Table 3 to its corresponding $\mathrm{S} / \mathrm{N}$ for the micro-hardness and wear volume, respectively. The $\mathrm{S} / \mathrm{N}$ conversion results for micro-hardness and wear volume are shown in Table 4 .

$$
\begin{gathered}
\frac{\mathrm{S}}{\mathrm{N}}=-10 \log \left(\frac{1}{\mathrm{n}} \sum_{\mathrm{i}=1}^{\mathrm{n}} \frac{1}{\mathrm{Y}_{\mathrm{i}}^{2}}\right)=-10 \log \left(\frac{1}{\mathrm{Y}_{\mathrm{i}}^{2}}\right) \\
\frac{\mathrm{S}}{\mathrm{N}}=-10 \log \left(\frac{1}{\mathrm{n}} \sum_{\mathrm{i}=1}^{\mathrm{n}} \mathrm{Y}_{\mathrm{i}}^{2}\right)=-10 \log \left(\mathrm{Y}_{\mathrm{i}}^{2}\right)
\end{gathered}
$$

where $\mathrm{n}$ is the number of replica for each run, as $\mathrm{n}=1$ in this study, Equation (1) and (2) are simplified as shown above; $Y_{i}(i=1,2,3, \ldots, 16)$ is the corresponding result in the ith run [32-35]. Afterwards, analysis of variance (ANOVA) was conducted to investigate the influence of different processing parameters on the micro-hardness and wear volume. The significance level, $\alpha$ was set at 0.05 . In the end, grey relational analysis was used in simultaneous multi-objectives optimization to achieve the maximal micro-hardness and minimal wear volume.

Table 4. Signal to noise ratio $(\mathrm{S} / \mathrm{N})$ conversion results for micro-hardness and wear volume.

\begin{tabular}{ccccc}
\hline Run & $\begin{array}{c}\text { Micro-Hardness } \\
\text { (HRC) }\end{array}$ & $\begin{array}{c}\text { S/N of } \\
\text { Micro-Hardness } \\
\mathbf{( d B )}\end{array}$ & $\begin{array}{c}\text { Wear Volume } \\
\left(\mathbf{m m}^{\mathbf{3}} \mathbf{)}\right.\end{array}$ & $\begin{array}{c}\text { S/N of Wear } \\
\text { Volume }(\mathbf{d B})\end{array}$ \\
\hline 1 & 19.0 & 25.575 & 0.0042296 & 47.474 \\
2 & 24.9 & 27.924 & 0.0034816 & 49.164 \\
3 & 39.1 & 31.844 & 0.0020500 & 53.765 \\
4 & 50.6 & 34.083 & 0.0016755 & 55.517 \\
5 & 40.0 & 32.041 & 0.0009220 & 60.705 \\
6 & 66.3 & 36.430 & 0.0003904 & 68.170 \\
7 & 37.1 & 31.387 & 0.0020868 & 53.610 \\
8 & 47.4 & 33.516 & 0.0003091 & 70.198 \\
9 & 18.0 & 25.105 & 0.0032789 & 49.685 \\
10 & 45.7 & 33.198 & 0.0008109 & 61.821 \\
11 & 25.6 & 28.165 & 0.0028956 & 50.765 \\
12 & 17.4 & 24.811 & 0.0032958 & 49.641 \\
13 & 47.8 & 33.589 & 0.0003133 & 70.081 \\
14 & 18.2 & 25.201 & 0.0054664 & 45.246 \\
15 & 57.9 & 35.254 & 0.0004863 & 66.262 \\
16 & 28.0 & 28.943 & 0.0039519 & 48.064 \\
\hline
\end{tabular}

\section{Results and Discussion}

\subsection{Analysis of Variance}

The test for normality is necessary before conducting analysis of variance (ANOVA), since large scale error may occur if the data set is not following normal distribution. The normality test was conducted by Anderson-Darling test in Minitab 17, where normal distribution was indicated when the $p$-value was larger than 0.05 [36]. From Figure 2 below, the $p$-values were both larger than 0.05 for the $\mathrm{S} / \mathrm{N}$ conversion of micro-hardness and wear volume in the Anderson-Darling test. Thus, normal distributions for both responses were verified, and ANOVA was conducted hereafter. 


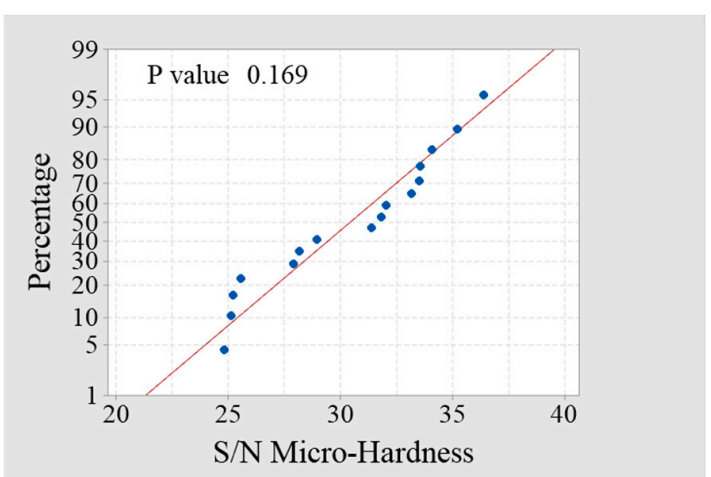

(a)

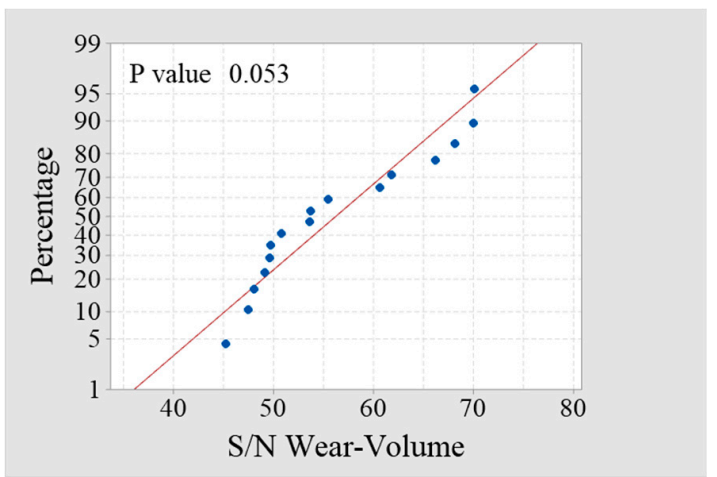

(b)

Figure 2. Test for normality regarding (a) $\mathrm{S} / \mathrm{N}$ of micro-hardness; (b) $\mathrm{S} / \mathrm{N}$ of wear volume.

\subsubsection{Analysis of Micro-Hardness}

The ANOVA analysis on the $\mathrm{S} / \mathrm{N}$ of micro-hardness is shown in Table 5 below. The $p$-value for SiC powder ratio was 0.001 , which was far less than the significance level 0.05 . Therefore, SiC powder ratio had significant influence on the micro-hardness during laser cladding. The contribution of SiC powder ratio was $92.08 \%$, which also indicated the micro-hardness was primarily affected by the SiC powder ratio, while the other processing parameters had negligible impact on the micro-hardness.

Table 5. ANOVA analysis on $\mathrm{S} / \mathrm{N}$ of micro-hardness.

\begin{tabular}{cccccccc}
\hline Source & DF & Seq SS & Adj SS & Adj MS & F Value & Contribute & $p$ Value \\
\hline LP & 3 & 5.307 & 5.379 & 1.7690 & 2.82 & $2.31 \%$ & 0.209 \\
SS & 3 & 7.796 & 7.787 & 2.5988 & 4.14 & $3.39 \%$ & 0.137 \\
GF & 3 & 3.216 & 3.210 & 1.0719 & 1.71 & $1.40 \%$ & 0.335 \\
PR & 3 & 211.550 & 212.006 & 70.5167 & 112.36 & $92.08 \%$ & 0.001 \\
Error & 3 & 1.883 & 1.873 & 0.6276 & & $0.82 \%$ & \\
Total & 15 & 229.752 & & & & $100 \%$ & \\
\hline
\end{tabular}

Table 6 was obtained by averaging the $\mathrm{S} / \mathrm{N}$ of micro-hardness in different levels for each factor. Delta represented the difference between the maximum and minimum value for each factor. The rank in the last row was the order by sorting the categorical delta value from largest to smallest. The main effects plot for $\mathrm{S} / \mathrm{N}$ of micro-hardness was generated by plotting the mean values in Table 6 for each factor, shown in Figure 3. The grey dash line was plotted as a reference line standing for the overall mean value for all the 16 samples. It was evident that the $\mathrm{SiC}$ powder ratio had the most significant impact on the micro-hardness, which was consistent with the ANOVA result in Table 5. The increase of $\mathrm{SiC}$ powder ratio brought a significant increase of micro-hardness. Since a larger $\mathrm{SiC}$ powder ratio indicated increased more $\mathrm{SiC}$ particles in the composite powder mixture were delivered for laser cladding, the amount of $\mathrm{Si}$ and $\mathrm{C}$ element decomposed from $\mathrm{SiC}$ in the molten pool was thus increased. Compounds were formed between the decomposed $\mathrm{Si}$ and $\mathrm{C}$ elements with the Fe and $\mathrm{Cr}$ elements from 316L stainless steel powder, which refined the grain and increased the micro-hardness $[16,37,38]$.

Table 6. Average $\mathrm{S} / \mathrm{N}$ of micro-hardness for each factor in different levels.

\begin{tabular}{ccccc}
\hline Level & Laser Power & Scanning Speed & Gas Flow & Powder Ratio \\
\hline 1 & 29.60 & 31.63 & 29.69 & 25.17 \\
2 & 31.01 & 30.24 & 30.62 & 29.11 \\
3 & 30.95 & 29.96 & 30.58 & 32.87 \\
4 & 30.21 & 29.94 & 30.87 & 34.62 \\
$\Delta$ & 1.41 & 1.69 & 1.18 & 9.46 \\
Rank & 3 & 2 & 4 & 1 \\
\hline
\end{tabular}




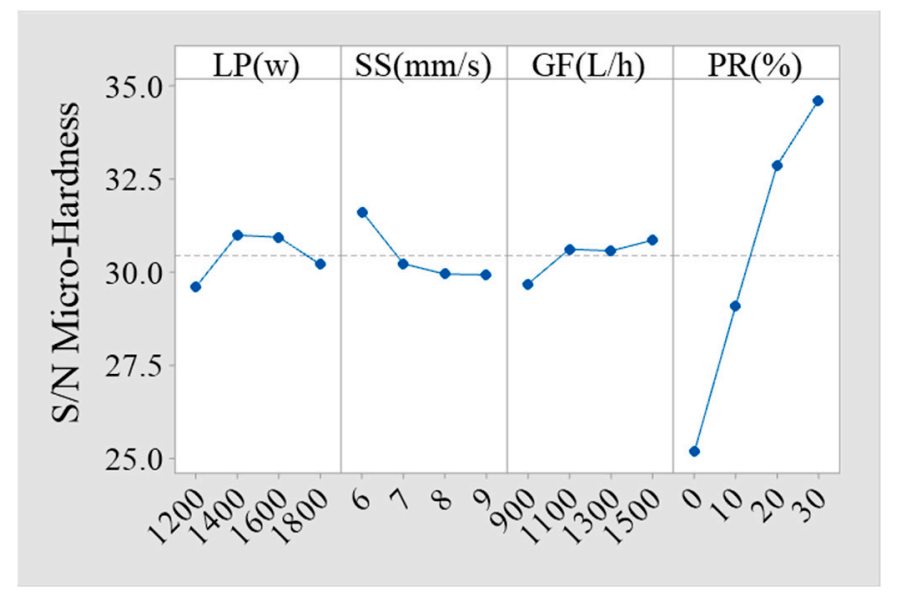

Figure 3. Main effects plot for the $\mathrm{S} / \mathrm{N}$ of micro-hardness.

\subsubsection{Analysis of Wear Volume}

Similarly, Table 7 shows the ANOVA result on S/N of wear volume. The $0.014 p$-value and $79.39 \%$ contribution from $\mathrm{SiC}$ powder ratio indicated its significant influence on wear volume during laser cladding process with $316 \mathrm{~L} / \mathrm{SiC}$ powder mixture, while the other processing parameters presented minimal impact.

Table 7. ANOVA analysis on $\mathrm{S} / \mathrm{N}$ of wear volume.

\begin{tabular}{cccccccc}
\hline Source & DF & Seq SS & Adj SS & Adj MS & F Value & Contribute & $p$ Value \\
\hline LP & 3 & 99.44 & 33.15 & 7.769 & 2.63 & $8.84 \%$ & 0.224 \\
SS & 3 & 59.17 & 19.72 & 7.553 & 1.57 & $5.26 \%$ & 0.360 \\
GF & 3 & 35.45 & 11.82 & 0.466 & 0.94 & $3.15 \%$ & 0.520 \\
PR & 3 & 893.12 & 297.71 & 293.140 & 23.66 & $79.39 \%$ & 0.014 \\
Error & 3 & 37.75 & 12.58 & 6.549 & & $3.36 \%$ & \\
Total & 15 & 1124.92 & & & & $100 \%$ & \\
\hline
\end{tabular}

Table 8 and Figure 4 exhibit the S/N of wear volume increased with the increasing $\mathrm{SiC}$ powder ratio. Since the $\mathrm{S} / \mathrm{N}$ of wear volume was converted using Equation (2), in which the wear volume was expected to be the smaller the better, the $\mathrm{S} / \mathrm{N}$ of wear volume was negatively correlated with the actual wear volume. In Figure 4, the increasing SiC powder ratio resulted in the increasing $\mathrm{S} / \mathrm{N}$ of wear volume, which in fact represented the decreasing of the actual wear volume on the clad. It is generally accepted that the wear resistance is related to the hardness of material [39]. According to Archard wear equation, the wear volume is negatively related to hardness [40]. Because of the larger SiC powder ratio promoted a larger micro-hardness, which improved the capability of the clad in resisting deformation by reducing the actual contact and rubbing area during scratching. Hence, the wear volume was decreased.

Table 8. Average $\mathrm{S} / \mathrm{N}$ of wear volume for each factor in different levels.

\begin{tabular}{ccccc}
\hline Level & Laser Power & Scanning Speed & Gas Flow & Powder Ratio \\
\hline 1 & 54.52 & 57.44 & 55.92 & 48.01 \\
2 & 56.37 & 57.42 & 56.59 & 50.62 \\
3 & 57.78 & 56.33 & 56.55 & 60.87 \\
4 & 57.03 & 54.52 & 56.65 & 66.20 \\
$\Delta$ & 3.26 & 2.92 & 0.74 & 18.19 \\
Rank & 2 & 3 & 4 & 1 \\
\hline
\end{tabular}




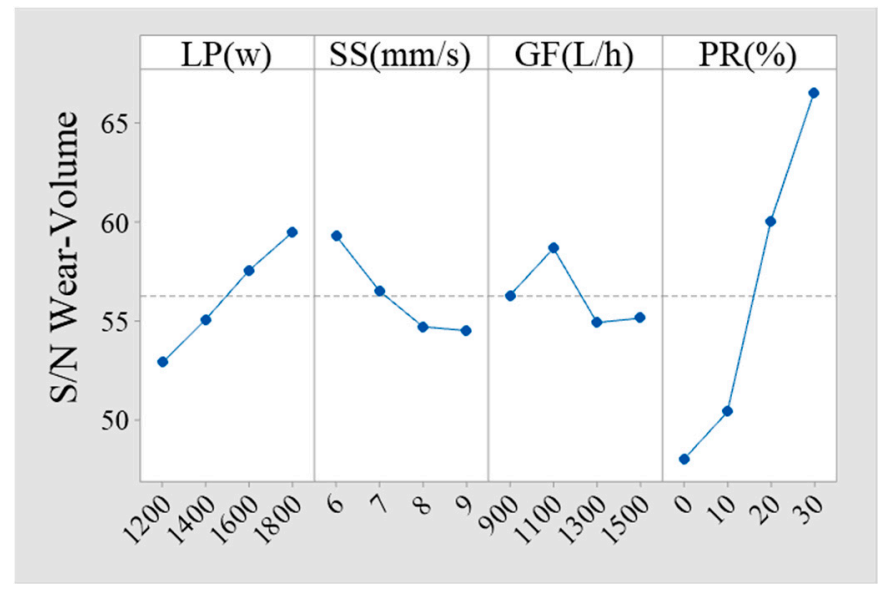

Figure 4. Main effects plot for the $\mathrm{S} / \mathrm{N}$ of wear volume.

\subsection{Multi-Objective Optimization Based on Grey Relational Analysis}

While ANOVA on the Taguchi orthogonal experimental design is suitable for single objective optimization, but it is ineffective in multi-objective optimization [41]. Julong Deng developed the grey relational analysis to complete the multi-objective optimization [42,43]. By combining the Taguchi orthogonal experimental design with grey relational analysis, analysis on the influence of multiple factors (all the processing parameters) and multi-objective optimization (maximize micro-hardness and minimize wear volume) are effectively able to accomplish at the same time [44].

The process of completing the multi-objective optimization in this study is summarized in three steps $[45,46]$. Step One is data normalization on the $\mathrm{S} / \mathrm{N}$ of micro-hardness and $\mathrm{S} / \mathrm{N}$ of wear volume. The data after normalization will range from 0 to 1 , regardless of its original unit and data range. Equations (3) and (4) below were used to conduct the data normalization for the data set of S/N of micro-hardness and $\mathrm{S} / \mathrm{N}$ of wear volume,

$$
\begin{aligned}
& X_{i}(\mathrm{SNMH})=\frac{Y_{\mathrm{i}}(\mathrm{SNMH})-\min \mathrm{Y}_{\mathrm{i}}(\mathrm{SNMH})}{\max \mathrm{Y}_{\mathrm{i}}(\mathrm{SNMH})-\min _{\mathrm{i}}(\mathrm{SNMH})} \\
& \mathrm{X}_{\mathrm{i}}(\mathrm{SNWV})=\frac{\mathrm{Y}_{\mathrm{i}}(\mathrm{SNWV})-\min \mathrm{Y}_{\mathrm{i}}(\mathrm{SNWV})}{\max \mathrm{Y}_{\mathrm{i}}(\mathrm{SNWV})-\min _{\mathrm{i}}(\mathrm{SNWV})}
\end{aligned}
$$

where $X_{i}$ represents the corresponding value after data normalization; $Y_{i}$ stands for the corresponding original results; $i$ is the ith experimental run $(i=1,2,3, \ldots, 16) ; \mathrm{SNMH}$ stands for $\mathrm{S} / \mathrm{N}$ of micro-hardness, and SNWV stands for $\mathrm{S} / \mathrm{N}$ of wear volume; $\min Y_{i}$ and $\max Y_{i}$ represent the minimum and maximum value of corresponding $\mathrm{Y}_{\mathrm{i}}$.

Step Two is grey relational coefficient calculation using Equations (5) and (6) for the data set of $\mathrm{S} / \mathrm{N}$ of micro-hardness and $\mathrm{S} / \mathrm{N}$ of wear volume,

$$
\begin{aligned}
& \mathrm{GRC}_{\mathrm{i}}(\mathrm{SNMH})=\frac{\min \Delta_{\mathrm{i}}(\mathrm{SNMH})+\xi \max \Delta_{\mathrm{i}}(\mathrm{SNMH})}{\Delta_{\mathrm{i}}(\mathrm{SNMH})+\xi \max \Delta_{\mathrm{i}}(\mathrm{SNMH})} \\
& \mathrm{GRC}_{\mathrm{i}}(\mathrm{SNWV})=\frac{\min \Delta_{\mathrm{i}}(\mathrm{SNWV})+\xi \max \Delta_{\mathrm{i}}(\mathrm{SNWV})}{\Delta_{\mathrm{i}}(\mathrm{SNWV})+\xi \max \Delta_{\mathrm{i}}(\mathrm{SNWV})}
\end{aligned}
$$

where $\mathrm{GRC}_{\mathrm{i}}$ stands for the grey relational coefficient (GRC) for the corresponding objectives in the $i$ th run; $\Delta_{i}$ is the corresponding deviation between the normalized value and the reference value 1 , which is obtained by equation $\Delta_{\mathrm{i}}(\mathrm{SNMH})=\left|1-\mathrm{X}_{\mathrm{i}}(\mathrm{SNMH})\right|$ and $\Delta_{\mathrm{i}}(\mathrm{SNWV})=\left|1-\mathrm{X}_{\mathrm{i}}(\mathrm{SNWV})\right| ; \min \Delta_{\mathrm{i}}$ and $\max \Delta_{\mathrm{i}}$ represent the corresponding minimum and maximum value of $\Delta_{\mathrm{i}} ; \xi$ is the distinguishing coefficient with the range $\xi \in[0,1]$. Because of the moderate distinguishing effect and stability, usually 
0.5 is selected for the value of $\xi$ [47]. The result of normalization and grey relational coefficient for each run are shown in Table 9.

Table 9. Normalization and grey relational coefficient for the data set.

\begin{tabular}{ccccc}
\hline \multirow{2}{*}{ Run } & \multicolumn{2}{c}{ Normalization } & \multicolumn{2}{c}{ Grey Relational Coefficient } \\
\cline { 2 - 5 } & $\begin{array}{c}\text { S/N of } \\
\text { Micro-Hardness }\end{array}$ & $\begin{array}{c}\text { S/N of Wear } \\
\text { Volume }\end{array}$ & $\begin{array}{c}\text { S/N of } \\
\text { Micro-Hardness }\end{array}$ & $\begin{array}{c}\text { S/N of Wear } \\
\text { Volume }\end{array}$ \\
\hline 1 & 0.068966 & 0.092000 & 0.349398 & 0.355114 \\
2 & 0.267241 & 0.160000 & 0.405594 & 0.373134 \\
3 & 0.612069 & 0.344000 & 0.563107 & 0.432526 \\
4 & 0.801724 & 0.412000 & 0.716049 & 0.459559 \\
5 & 0.620690 & 0.620000 & 0.568627 & 0.568182 \\
6 & 1.000000 & 0.920000 & 1.000000 & 0.862069 \\
7 & 0.568966 & 0.336000 & 0.537037 & 0.429553 \\
8 & 0.750000 & 1.000000 & 0.666667 & 1.000000 \\
9 & 0.025862 & 0.180000 & 0.339181 & 0.378788 \\
10 & 0.724138 & 0.664000 & 0.644444 & 0.598086 \\
11 & 0.293103 & 0.224000 & 0.414286 & 0.391850 \\
12 & 0.000000 & 0.176000 & 0.333333 & 0.377644 \\
13 & 0.758621 & 0.996000 & 0.674419 & 0.992063 \\
14 & 0.034483 & 0.000000 & 0.341176 & 0.333333 \\
15 & 0.905172 & 0.844000 & 0.840580 & 0.762195 \\
16 & 0.353448 & 0.116000 & 0.436090 & 0.361272 \\
\hline
\end{tabular}

The last step is calculating the grey relational grade (GRG). The goal of this study is improving the micro-hardness of the clad layer, while reducing the wear volume at the same time, so that the high performance clad layer could be obtained. Therefore, equivalent weight factor was assigned to both objectives and the GRG calculation was conducted using Equation (7),

$$
\mathrm{GRG}_{\mathrm{i}}=\frac{\mathrm{GRC}_{\mathrm{i}}(\mathrm{SNMH})+\mathrm{GRC}_{\mathrm{i}}(\mathrm{SNWV})}{2}
$$

where $\mathrm{GRG}_{\mathrm{i}}$ is the grey relational grade for the ith run. After all the GRGs for the 16 runs were derived, $\mathrm{S} / \mathrm{N}$ conversion was conducted using Equation (1) and the converted values were sorted from largest to smallest as the rank in last column in Table 10. A larger GRG and its corresponding S/N GRG indicate attaining the preferable micro-hardness and wear volume concurrently. Thus, the best experiment setup in the L16 Taguchi orthogonal design was the 6th run, which consisted a laser power of $1400 \mathrm{~W}$, scanning speed of $7 \mathrm{~mm} / \mathrm{s}$, gas flow of $1500 \mathrm{~L} / \mathrm{h}$, and $\mathrm{SiC}$ powder ratio of $30 \%$.

Table 10. Grey relational grade and the corresponding $\mathrm{S} / \mathrm{N}$ conversion.

\begin{tabular}{cccc}
\hline Run & GRG & S/N of GRG & Rank \\
\hline 1 & 0.352256 & -9.062842 & 15 \\
2 & 0.389364 & -8.192876 & 12 \\
3 & 0.497816 & -6.058616 & 8 \\
4 & 0.587804 & -4.615348 & 6 \\
5 & 0.568405 & -4.906848 & 7 \\
6 & 0.931034 & -0.620685 & 1 \\
7 & 0.483295 & -6.315751 & 9 \\
8 & 0.833333 & -1.583625 & 2 \\
9 & 0.358985 & -8.898484 & 13 \\
10 & 0.621265 & -4.134458 & 5 \\
11 & 0.403068 & -7.892442 & 10 \\
12 & 0.355488 & -8.983491 & 14 \\
13 & 0.833241 & -1.584587 & 3 \\
14 & 0.337255 & -9.440835 & 4 \\
15 & 0.801387 & -1.923150 & 11 \\
16 & 0.398681 & -7.987490 & \\
\hline
\end{tabular}


Figure 5 shows the Anderson-Darling test for normality on the $\mathrm{S} / \mathrm{N}$ of GRG, its p-value is larger than 0.05 . Thus, the normal distribution hypothesis is accepted. The ANOVA result is showing in Table 11 below. From the $p$-value of each processing parameters, it can conclude that laser power, scanning speed and $\mathrm{SiC}$ powder ratio had significant influence on the grey relational grade, when larger micro-hardness and less wear volume were desired concurrently. Gas flow displayed statistically insignificant based on its $p$-value.

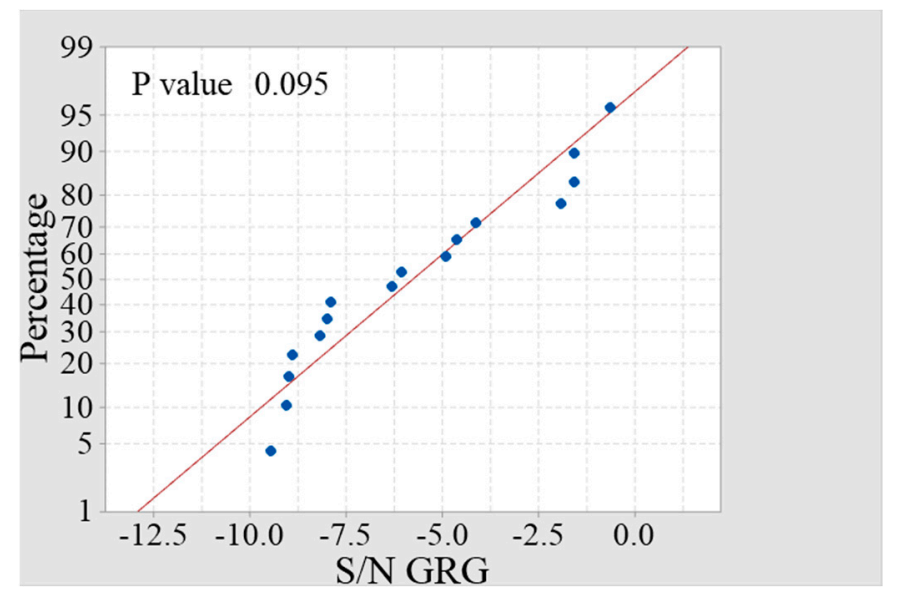

Figure 5. Test for normality on $\mathrm{S} / \mathrm{N}$ of grey relational grade (GRG).

Table 11. ANOVA analysis on S/N of GRG.

\begin{tabular}{cccccccc}
\hline Source & DF & Seq SS & Adj SS & Adj MS & F Value & Contribute & $p$ Value \\
\hline LP & 3 & 7.458 & 7.458 & 2.4861 & 22.65 & $5.28 \%$ & 0.015 \\
SS & 3 & 9.900 & 9.900 & 3.2999 & 30.06 & $7.01 \%$ & 0.010 \\
GF & 3 & 2.279 & 2.279 & 0.7597 & 6.92 & $1.61 \%$ & 0.073 \\
PR & 3 & 121.248 & 121.248 & 40.4161 & 368.19 & $85.86 \%$ & $<0.001$ \\
Error & 3 & 0.329 & 0.329 & 0.1098 & & $0.23 \%$ & \\
Total & 15 & 141.215 & & & & $100 \%$ & \\
\hline
\end{tabular}

The average of S/N GRG for each of the four processing parameters in their four different levels were shown in Table 12. Delta stands for the absolute difference between maximum and minimum for each factor. From the sorting rank (largest to smallest), it can conclude that the influence on GRG was following the order of $\mathrm{SiC}$ powder ratio, scanning speed, laser power, then gas flow as the last. The maximum value in each category provided the possible optimal set point to achieve the desired $\mathrm{GRG}$, which was $\mathrm{LP}_{\text {level } 4}, \mathrm{SS}_{\text {level } 1}, \mathrm{GF}_{\text {level 2 }}, \mathrm{PR}_{\text {level } 4}$, referring to $1800 \mathrm{~W}$ laser power, $6 \mathrm{~mm} / \mathrm{s}$ scanning speed, $1100 \mathrm{~L} / \mathrm{h}$ gas flow, and $30 \% \mathrm{SiC}$ powder ratio. Since this set of processing parameters is not in the original L16 Taguchi orthogonal design setup, experimental validation is necessary to verify this prediction.

Table 12. Average S/N of GRG for each factor in different levels.

\begin{tabular}{ccccc}
\hline Level & Laser Power & Scanning Speed & Gas Flow & Powder Ratio \\
\hline 1 & -6.882 & -4.490 & -6.031 & -9.096 \\
2 & -5.623 & -5.748 & -5.116 & -7.597 \\
3 & -5.511 & -6.290 & -5.891 & -4.291 \\
4 & -5.035 & -6.523 & -6.012 & -2.066 \\
$\Delta$ & 1.847 & 2.033 & 0.916 & 7.031 \\
Rank & 3 & 2 & 4 & 1 \\
\hline
\end{tabular}




\subsection{Experimental Validation on the Predicted Optimal Setting}

Equation (8) was used to predict the GRG before the validation experiment conducting under the aforementioned processing parameters:

$$
\mathrm{GRG}_{\text {prediction }}=\overline{\mathrm{GRG}_{\text {total }}}+\sum_{\mathrm{j}=1}^{\mathrm{q}}\left(\overline{\mathrm{GRG}_{\mathrm{j}}}-\overline{\mathrm{GRG}_{\text {total }}}\right)
$$

where $\mathrm{GRG}_{\text {prediction }}$ is the predicted GRG; $\overline{\mathrm{GRG}_{\text {total }}}$ stands for the mean of total GRG; $q$ is the total number of processing parameters, which is four in this study; $\overline{\mathrm{GRG}_{j}}$ is the average GRG value at the desired level for the $j$ th processing parameter. After calculation, the predicted GRG at the desired level of processing parameters is found to be 1 .

Afterwards, the validation experiment was conducted under the predicted optimal set point. The derived micro-hardness, wear volume and GRG are shown in Table 13. Compared to the best experiment setup in the original L16 Taguchi orthogonal design (6th run), the micro-hardness was improved from $66.3 \mathrm{HRC}$ to $68.9 \mathrm{HRC}$, which was $3.92 \%$ improvement. Similarly, the wear volume was reduced from $0.0003904 \mathrm{~mm}^{3}$ to $0.0003121 \mathrm{~mm}^{3}$, which was $25.09 \%$ improvement. The error rate between predicted GRG and experimental validated GRG was $5.3 \%$. This result indicates the processing parameter set obtained from grey relation analysis bring the improvement on both responses of micro-hardness and wear resistance. In addition, the prediction of grey relation grade also displays favorable accuracy.

Table 13. Experimental validation result and comparison.

\begin{tabular}{|c|c|c|c|c|}
\hline Variables/Responses & Input/Output & 6th Run in $\mathrm{L}_{16}$ Design & Optimal Set Prediction & Validation \\
\hline \multirow{4}{*}{ Processing Parameters } & Laser Power $(\mathrm{W})$ & 1400 & 1800 & 1800 \\
\hline & Scanning Speed $(\mathrm{mm} / \mathrm{s})$ & 7 & 6 & 6 \\
\hline & Gas Flow $(\mathrm{L} / \mathrm{h})$ & 1500 & 1100 & 1100 \\
\hline & SiC Powder Ratio (\%) & 30 & 30 & 30 \\
\hline \multirow{3}{*}{ Outcomes } & Micro-Hardness (HRC) & 66.3 & - & 68.9 \\
\hline & Wear Volume $\left(\mathrm{mm}^{3}\right)$ & 0.0003904 & - & 0.0003121 \\
\hline & GRG & 0.931034 & 1 & 0.949887 \\
\hline
\end{tabular}

\section{Conclusions}

This paper used the Taguchi orthogonal experiment design, investigated the influence of laser power, scanning speed, gas flow, and $\mathrm{SiC}$ powder ratio on the micro-hardness and wear volume in the cladding layer. Based on the signal to noise ratio conversion, this study applied grey relational analysis to achieve the optimization on multiple objectives simultaneously. The predicted processing parameters set was verified through experimental validation. Conclusions are addressed as follows:

1. The analysis on the micro-hardness alone indicates it was primarily affected by the SiC powder ratio, while other processing parameters were shown to be statistically insignificant. The micro-hardness of cladding layer was improved with the increasing $\mathrm{SiC}$ powder ratio.

2. The analysis on the wear volume by itself also shows the primarily influence from the $\mathrm{SiC}$ powder ratio, while other processing parameters were statistically insignificant. The wear volume of cladding layer was reduced with the increasing $\mathrm{SiC}$ powder ratio.

3. The contribution of $\mathrm{SiC}$ powder ratio on the micro-hardness and wear volume in their corresponding ANOVA was $92.08 \%$ and $79.39 \%$, respectively. This indicates that the micro-hardness and wear volume were primarily affected by $\mathrm{SiC}$ powder ratio and other processing parameters had a negligible impact.

4. Grey relational analysis was applied to achieve the objective of maximizing micro-hardness while minimizing wear volume simultaneously. The processing parameters set fulfilling this target was $1800 \mathrm{~W}$ laser power, $6 \mathrm{~mm} / \mathrm{s}$ scanning speed, $110 \mathrm{~L} / \mathrm{h}$ gas flow, and 30\% $\mathrm{SiC}$ powder ratio. 
5. The grey relational grade was predicted and then experimentally validated in the multi-objectives grey relational analysis. The error rate was $5.3 \%$ between predicted value and actual value. It validates the applicability of applying grey relational analysis on multi-objectives optimization.

Author Contributions: Methodology, G.L. and C.Z.; experiment, C.Z.; analysis, G.L., C.Z., Y.Z., M.F., and J.J.; writing-original draft preparation, G.L. and C.Z.; writing-review and editing, G.L. and Y.Z.; supervision, G.L. and Y.Z. All authors have read and agreed to the published version of the manuscript.

Funding: This research was funded by the National Natural Science Foundation of China (Grant No. 51575110), and the Fujian Provincial Education and Research Program for Young and Middle-Aged Teachers (Grant No. JAT190407).

Acknowledgments: The authors gratefully acknowledge the support from the Public Service Platform for Technical Innovation of Machine Tool Industry in Fujian Province at Fujian University of Technology.

Conflicts of Interest: The authors declare no conflicts of interest.

\section{References}

1. Gao, W.; Chang, C.; Li, G.; Xue, Y.; Wang, J.; Zhang, Z.; Lin, X. Study on the laser cladding of FeCrNi coating. Optik 2019, 178, 950-957. [CrossRef]

2. Roy, T.; Abrahams, R.; Paradowska, A.; Lai, Q.; Mutton, P.; Soodi, M.; Fasihi, P.; Yan, W. Evaluation of the mechanical properties of laser cladded hypereutectoid steel rails. Wear 2019, 432, 202930. [CrossRef]

3. Huang, H.; Sun, W.; Huang, Y.; Yu, J. Properties of Curved Parts Laser Cladding Based on Controlling Spot Size. Appl. Sci. 2020, 10, 728. [CrossRef]

4. Alam, M.K.; Urbanic, J.; Nazemi, N.; Edrisy, A. Predictive modeling and the effect of process parameters on the hardness and bead characteristics for laser-cladded stainless steel. Int. J. Adv. Manuf. Technol. 2017, 94, 397-413. [CrossRef]

5. Zhou, S.; Xu, Y.; Liao, B.; Sun, Y.; Dai, X.; Yang, J.; Li, Z. Effect of laser remelting on microstructure and properties of WC reinforced Fe-based amorphous composite coatings by laser cladding. Opt. Laser Technol. 2018, 103, 8-16. [CrossRef]

6. Zhu, Y.; Yang, Y.; Mu, X.; Wang, W.; Yao, Z.; Yang, H. Study on wear and RCF performance of repaired damage railway wheels: Assessing laser cladding to repair local defects on wheels. Wear 2019, 430, 126-136. [CrossRef]

7. Liu, D.; Zhao, J.; Li, Y.; Zhu, W.; Lin, L. Effects of Boron Content on Microstructure and Wear Properties of FeCoCrNiBx High-Entropy Alloy Coating by Laser Cladding. Appl. Sci. 2019, 10, 49. [CrossRef]

8. He, B.; Zhang, L.; Zhu, Q.; Wang, J.; Yun, X.; Luo, J.; Chen, Z. Effect of solution treated 316L layer fabricated by laser cladding on wear and corrosive wear resistance. Opt. Laser Technol. 2020, 121, 105788. [CrossRef]

9. Sun, G.F.; Shen, X.; Wang, Z.; Zhan, M.; Yao, S.; Zhou, R.; Ni, Z. Laser metal deposition as repair technology for 316L stainless steel: Influence of feeding powder compositions on microstructure and mechanical properties. Opt. Laser Technol. 2019, 109, 71-83. [CrossRef]

10. Li, C.; Zhang, Q.; Wang, F.; Deng, P.; Lu, Q.; Zhang, Y.; Li, S.; Ma, P.; Li, W.; Wang, Y. Microstructure and wear behaviors of WC-Ni coatings fabricated by laser cladding under high frequency micro-vibration. Appl. Surf. Sci. 2019, 485, 513-519. [CrossRef]

11. Javadhesari, S.M.; Alipour, S.; Akbarpour, M. Microstructural characterization and enhanced hardness, wear and antibacterial properties of a powder metallurgy SiC/Ti-Cu nanocomposite as a potential material for biomedical applications. Ceram. Int. 2019, 45, 10603-10611. [CrossRef]

12. Wen, X.; Jin, G.; Cui, X.; Feng, X.; Lu, B.; Cai, Z.; Zhao, Y.; Fang, Y. Underwater wet laser cladding on 316L stainless steel: A protective material assisted method. Opt. Laser Technol. 2019, 111, 814-824. [CrossRef]

13. Mei, X.; Wang, X.; Peng, Y.; Gu, H.; Zhong, G.; Yang, S. Interfacial characterization and mechanical properties of 316L stainless steel/inconel 718 manufactured by selective laser melting. Mater. Sci. Eng. A 2019, 758, 185-191. [CrossRef]

14. Murkute, P.; Pasebani, S.; Isgor, O.B. Production of corrosion-resistant 316L stainless steel clads on carbon steel using powder bed fusion-selective laser melting. J. Mater. Process. Technol. 2019, 273, 116243. [CrossRef]

15. Riquelme, A.; Rodrigo, P.; Escalera-Rodríguez, M.D.; Rams, J. Characterisation and mechanical properties of $\mathrm{Al} / \mathrm{SiC}$ metal matrix composite coatings formed on ZE41 magnesium alloys by laser cladding. Results Phys. 2019, 13, 102160. [CrossRef] 
16. Ramakrishnan, A.; Dinda, G.P. Functionally graded metal matrix composite of Haynes 282 and SiC fabricated by laser metal deposition. Mater. Des. 2019, 179, 107877. [CrossRef]

17. Zhao, X.; Gu, D.; Ma, C.; Xi, L.; Zhang, H. Microstructure characteristics and its formation mechanism of selective laser melting $\mathrm{SiC}$ reinforced Al-based composites. Vacuum 2019, 160, 189-196. [CrossRef]

18. Ma, M.; Xiong, W.; Lian, Y.; Han, D.; Zhao, C.; Zhang, J. Modeling and optimization for laser cladding via multi-objective quantum-behaved particle swarm optimization algorithm. Surf. Coatings Technol. 2020, 381, 125129. [CrossRef]

19. Sohrabpoor, H. Analysis of laser powder deposition parameters: ANFIS modeling and ICA optimization. Optik 2016, 127, 4031-4038. [CrossRef]

20. Shi, Y.; Li, Y.; Liu, J.; Yuan, Z. Investigation on the parameter optimization and performance of laser cladding a gradient composite coating by a mixed powder of Co50 and Ni/WC on 20CrMnTi low carbon alloy steel. Opt. Laser Technol. 2018, 99, 256-270. [CrossRef]

21. Zhao, S.; Shen, X.; Yang, J.; Teng, W.; Wang, Y. Densification behavior and mechanical properties of nanocrystalline $\mathrm{TiC}$ reinforced 316L stainless steel composite parts fabricated by selective laser melting. Opt. Laser Technol. 2018, 103, 239-250. [CrossRef]

22. Salman, O.; Gammer, C.; Eckert, J.; Salih, M.; Abdulsalam, E.; Prashanth, K.; Scudino, S. Selective laser melting of 316L stainless steel: Influence of TiB2 addition on microstructure and mechanical properties. Mater. Today Commun. 2019, 21, 100615. [CrossRef]

23. Wang, K.; Chang, B.; Chen, J.; Fu, H.; Lin, Y.; Lei, Y. Effect of Molybdenum on the Microstructures and Properties of Stainless Steel Coatings by Laser Cladding. Appl. Sci. 2017, 7, 1065. [CrossRef]

24. Lian, G.; Zhang, H.; Zhang, Y.; Yao, M.; Huang, X.; Chen, C. Computational and Experimental Investigation of Micro-Hardness and Wear Resistance of Ni-Based Alloy and TiC Composite Coating Obtained by Laser Cladding. Materials 2019, 12, 793. [CrossRef] [PubMed]

25. Lian, G.; Zhao, C.; Zhang, Y.; Huang, X.; Chen, C.; Jiang, J. Investigation of Micro-Hardness, Wear Resistance, and Defects of 316L Stainless Steel and TiC Composite Coating Fabricated by Laser Engineered Net Shaping. Coatings 2019, 9, 498. [CrossRef]

26. Terzioğlu, H. Analysis of effect factors on thermoelectric generator using Taguchi method. Measurement 2020, 149, 106992. [CrossRef]

27. Lian, G.; Zhang, H.; Zhang, Y.; Tanaka, M.L.; Chen, C.; Jiang, J. Optimizing Processing Parameters for Multi-Track Laser Cladding Utilizing Multi-Response Grey Relational Analysis. Coatings 2019, 9, 356. [CrossRef]

28. Ilo, S.; Just, C.; Xhiku, F. Optimisation of multiple quality characteristics of hardfacing using grey-based Taguchi method. Mater. Des. 2012, 33, 459-468. [CrossRef]

29. Kumar, S.R.; Kulkarni, S.K. Analysis of Hard Machining of Titanium Alloy by Taguchi Method. Mater. Today Proc. 2017, 4, 10729-10738. [CrossRef]

30. Vempati, S.R.; Raju, K.B.; Subbaiah, K.V. Optimization of Welding Parameters of Ti 6al 4v Cruciform shape Weld joint to Improve Weld Strength Based on Taguchi Method. Mater. Today Proc. 2018, 5, 4948-4957. [CrossRef]

31. Naik, A.B.; Reddy, A.C. Optimization of tensile strength in TIG welding using the Taguchi method and analysis of variance (ANOVA). Therm. Sci. Eng. Prog. 2018, 8, 327-339. [CrossRef]

32. Arıc1, E.; Keleştemur, O. Optimization of mortars containing steel scale using Taguchi based grey relational analysis method. Constr. Build. Mater. 2019, 214, 232-241. [CrossRef]

33. Derdour, F.Z.; Kezzar, M.; Khochemane, L.; Khochmane, L. Optimization of penetration rate in rotary percussive drilling using two techniques: Taguchi analysis and response surface methodology (RMS). Powder Technol. 2018, 339, 846-853. [CrossRef]

34. Ghalme, S.; Mankar, A.; Bhalerao, Y. Integrated Taguchi-simulated annealing (SA) approach for analyzing wear behaviour of silicon nitride. J. Appl. Res. Technol. 2017, 15, 624-632. [CrossRef]

35. Li, Y.; Zhu, L. Optimization of user experience in mobile application design by using a fuzzy analytic-network-process-based Taguchi method. Appl. Soft Comput. 2019, 79, 268-282. [CrossRef]

36. Das, A.; Patel, S.; Biswal, B.; Sahoo, N.; Pradhan, A. Performance evaluation of various cutting fluids using MQL technique in hard turning of AISI 4340 alloy steel. Measurement 2020, 150, 107079. [CrossRef]

37. Hulka, I.; Utu, D.; Serban, V.; Negrea, P.; Lukáč, F.; Chráska, T. Effect of Ti addition on microstructure and corrosion properties of laser cladded WC-Co/NiCrBSi(Ti) coatings. Appl. Surf. Sci. 2020, 504, 144349. [CrossRef]

38. Geng, Y.; Lin, X.; Li, J.; Fan, S.; Ju, H.; Yu, L.; Xu, J.; Wang, Y. Super-high hardness of (Fe,Co)-B-Si-Zr/Hf bulk glassy alloys. J. Alloy. Compd. 2018, 753, 351-355. [CrossRef] 
39. Zambrano, O.A.; Gómez, J.; Coronado, J.; Rodríguez, S. The sliding wear behaviour of steels with the same hardness. Wear 2019, 418, 201-207. [CrossRef]

40. Archard, J.F. Contact and Rubbing of Flat Surfaces. J. Appl. Phys. 1953, 24, 981. [CrossRef]

41. Yu, T.; Yang, L.; Zhao, Y.; Sun, J.; Li, B. Experimental research and multi-response multi-parameter optimization of laser cladding Fe313. Opt. Laser Technol. 2018, 108, 321-332. [CrossRef]

42. Deng, J. Control problems of grey systems. Syst. Control Lett. 1982, 1, 288-294.

43. Deng, J. Introduction to grey system theory. J. Grey Syst. 1989, 1, 1-24.

44. Mia, M.; Rifat, A.; Tanvir, F.; Gupta, M.K.; Hossain, J.; Goswami, A.; Dip, F.T. Multi-objective optimization of chip-tool interaction parameters using Grey-Taguchi method in MQL-assisted turning. Measurement 2018, 129, 156-166. [CrossRef]

45. Dodo, R.; Ause, T.; Dauda, E.; Shehu, U.; Popoola, A. Multi-response optimization of transesterification parameters of mahogany seed oil using grey relational analysis in Taguchi method for quenching application. Heliyon 2019, 5, e02167. [CrossRef] [PubMed]

46. Bademlioglu, A.; Canbolat, A.; Kaynakli, O. Multi-objective optimization of parameters affecting Organic Rankine Cycle performance characteristics with Taguchi-Grey Relational Analysis. Renew. Sustain. Energy Rev. 2020, 117, 109483. [CrossRef]

47. Prakash, B.; Raju, K.B.; Subbaiah, K.V.; Krishnamachary, P.; Manikandan, N.; Ramya, V. Application of Taguchi based Grey Method for Multi Aspects Optimization on CNC Turning of AlSi7 Mg. Mater. Today Proc. 2018, 5, 14292-14301. [CrossRef]

(C) 2020 by the authors. Licensee MDPI, Basel, Switzerland. This article is an open access article distributed under the terms and conditions of the Creative Commons Attribution (CC BY) license (http://creativecommons.org/licenses/by/4.0/). 